\title{
Osificación heterotópica de cadera asociada a pancreatitis aguda severa - reporte de un caso
}

\section{Hip Heterotopic Ossification Associated with Severe Acute Pancreatitis - A Case Report}

\author{
José Palma C. ${ }^{1}$ Samuel Parra A. ${ }^{1} \quad$ Yocelin Saavedra B. ${ }^{1} \quad$ Cristian San Martín L. $^{1} \quad$ Francisco Muñoz C. ${ }^{1}$ \\ Fabián Padilla M. ${ }^{1}$ \\ ${ }^{1}$ Traumatólogo Hospital Traumatológico de Concepción, Universidad \\ de Concepción, Concepción, Chile \\ Address for correspondence Dr. José Palma Concha, MD, San Martín \\ 1580., Región del Bío - Bío. Concepción, Chile \\ (e-mail: jose.palma.concha@gmail.com).
}

Rev Chil Ortop Traumatol 2019;60:27-31.

\section{Resumen \\ Palabras clave \\ - osificación heterotópica \\ - cuidados intensivos \\ - inmovilización}

La osificación heterotópica $(\mathrm{OH})$, es la formación anormal de hueso maduro dentro de tejidos blandos extra esqueléticos donde normalmente no existe tejido óseo. Varias formas de $\mathrm{OH}$ han sido descritas de acuerdo a su presentación clínica, localización y ocurrencia progresiva o aislada. Su presentación en pacientes sometidos a inmovilización prolongada en el contexto de coma farmacológicamente inducido, en ausencia de lesiones del sistema nervioso central, es poco habitual. Presentamos el caso de una paciente de 40 años, sexo femenino, sin antecedentes mórbidos, que presenta episodio de pancreatitis aguda grave, manejada en $\mathrm{UCl}$. Producto de lo anterior, requiere coma farmacológicamente inducido por 3 meses y hospitalizaciones reiteradas y prolongadas durante los 10 meses siguientes. Durante 3 años desde la resolución de su cuadro inicial evoluciona con alteración progresiva de la marcha y rigidez de la extremidad inferior derecha, sin eventos traumáticos durante ese período. Se objetiva mediante radiografía y TAC foco de $\mathrm{OH}$ coxofemoral derecha. Se resuelve de forma quirúrgica y biopsia de pieza operatoria confirma el diagnóstico. La paciente logra buena recuperación posterior.

Nivel de evidencia IV

Heterotopic ossification $(\mathrm{HO})$ is the abnormal formation of mature bone within extraskeletal soft tissues where bone does not exist. Various presentation of HO have been described according to the clinical settings and location of the lesions, and progressive or isolated occurrence. A rare form of presentation occurs in induced coma patients with long-term immobilization and without central nervous system injuries. We present the case of a 40 years old female patient, without previous morbidity, who develop a severe acute pancreatitis. The patient requires an intensive care unit management (ICU) and a 3-month pharmacology induced coma and reiterative and prolonged hospitalizations during the next 8 months. During 3 years after resolution of her base disease, patient develops a progressive step claudication and a hip rigidity in adduction and external rotation. A coxofemoral $\mathrm{HO}$ focus is confirmed by radiology and CT. A surgical treatment of HO was performed, and the initial diagnose confirmed by anatomic pathology after biopsy of the injury. Patient had a favorable outcome. received

October 17, 2018

accepted

February 11, 2019

published online

March 20, 2019
DOI https://doi.org/

10.1055/s-0039-1683894. ISSN 0716-4548.
Copyright (e 2019 by Thieme Revinter

Publicações Ltda, Rio de Janeiro, Brazil
License terms

(c) (1) $\ominus$ (5) 


\section{Introducción}

La osificación heterotópica $(\mathrm{OH})$ es la formación anormal de hueso maduro dentro de tejidos blandos extra esqueléticos. Su etiología involucra una serie de mecanismos moleculares relacionados con el proceso inflamatorio que terminan en activación anormal de osteoblastos y la producción de matriz ósea ectópica. Su descripción inicial fue realizada en 1883 por Reidel y luego en 1918 por Dejerne y Cellier. ${ }^{1}$ La OH en sus formas más severas puede causar Anquilosis.

Existen diversas formas de $\mathrm{OH}$ descritas en la literatura de acuerdo a su presentación clínica, localización de las lesiones y su ocurrencia progresiva o aislada. Ellas incluyen además $\mathrm{OH}$ traumáticas y no traumáticas. Entre ellas, y solo a modo de reseña encontramos: $\mathrm{OH}$ consecutiva a daño neurológico espinal o cerebral, Poliomielitis, Tétanos, Síndrome de Guillain-Barré y Paniculitis osificante. ${ }^{2}$ La presentación de $\mathrm{OH}$ en pacientes bajo sedación profunda, con consecuente inmovilización prolongada y en ausencia de lesiones del sistema nervioso central es inusual. ${ }^{3}$

Se presenta el caso de una paciente de 40 años, quien posterior a episodio de pancreatitis aguda (PA) grave, con manejo en unidad de cuidados intensivos (UCI) y requiriendo coma farmacológicamente inducido durante 3 meses, desarrolla durante los 3 años posteriores al evento inicial y sin mediar eventos traumáticos durante el periodo, $\mathrm{OH}$ de cadera derecha. Ésta se resuelve en forma quirúrgica.

\section{Caso clínico}

El presente caso clínico fue revisado y aprobado por el Comité de Ética de la Investigación en Seres Humanos del Hospital Traumatológico de Concepción, con el debido consentimiento informado, aprobado por la paciente.

Presentamos el caso de un paciente femenino de 40 años sin antecedentes mórbidos, quien en febrero 2007 presenta cuadro compatible con PA que cumplía criterios diagnósticos del Síndrome de Respuesta Inflamatoria Sistémica. Se confirma severidad con TAC, que describe PA necrohemorrágica severa de origen litiásico. Producto del deterioro hemodinámico por shock séptico, la paciente requiere manejo en UCI. Evoluciona en forma tórpida, con necesidad de múltiples laparotomías para aseos quirúrgicos, además de drogas vasoactivas y ventilación mecánica invasiva, para lo que se induce coma farmacológico. La paciente permanece en esa situación por un lapso de tres meses. Al término de ese periodo, consigue cicatrización adecuada de las heridas y resolución del proceso infeccioso, retirándose progresivamente las drogas vasoactivas y la ventilación mecánica. En mayo de 2007 egresa de UCI. Una vez en sala, presenta nuevas complicaciones (respiratorias y urinarias). Finalmente, luego de 10 meses de hospitalización es dada de alta en enero de 2008. Durante su hospitalización, se realizan sesiones diarias de fisioterapia, con movilización pasiva y activa progresiva, ejercicios de fortalecimiento de tren motor y marcha.

Entre 2008 y 2012 continúa con los controles en Gastroenterología por déficit enzimático pancreático y Diabetes Mellitus tipo 2. Ante las progresivas molestias y el dolor referido por la paciente en relación a la movilidad de la cadera derecha y claudicación franca, es derivada a policlínico de Traumatología. El examen físico evidencia Log Roll test positivo en cadera derecha, flexión limitada a $70^{\circ}$, extensión completa, abducción $20^{\circ}$, rotación externa $20^{\circ}$, sin signos de compromiso neurovascular en la extremidad. Radiografía de cadera derecha ( $\mathbf{- F i g . 1 A}$ ) evidencia proceso óseo dismórfico, con patrón de calcificación establecido y corticales bien definidas que abarca desde la rama pubiana derecha hasta la unión metafisodiafisiaria proximal del fémur derecho, con aparente anquilosis de cadera derecha. Se complementa estudio con TAC de Pelvis, donde se aprecia puente de $\mathrm{OH}$ coxofemoral anterior, uniendo acetábulo y trocánter menor del fémur derecho, con anquilosis incipiente.

Durante 2013 y derivado de la cicatriz de laparotomía, la paciente desarrolla hernia incisional en la pared abdominal que requirió reintervención quirúrgica, lo que postergó su tratamiento por Traumatología. Finalmente, en 2015 y con sus patologías crónicas compensadas, retoma los controles con dicha especialidad. Se solicitan nuevas radiografías de pelvis y de cadera derecha, además de TAC de pelvis (-Fig. 1B-E) que sugieren proceso compatible con $\mathrm{OH}$ derecha, situándose en cercanía de los vasos femorales.

En junio de 2016, se realiza cirugía de resección en conjunto con Cirujano Vascular a través de un abordaje femoral anteromedial incurvado, se diseca hasta exponer la bifurcación de los vasos femorales superficial y profundo, se protegen, y luego se accede a la osificación exponiéndola en forma subperióstica. Se reseca gran parte de la $\mathrm{OH}$ con sierra y cinceles. Se envían tres fragmentos cilíndricos de tejido óseo de 45, 62 y $55 \mathrm{~mm}$ de diámetro para estudio histológico, que confirma $\mathrm{OH}$. Al alta se inicia tratamiento con inhibidores de la Cox-2, específicamente Celecoxib, con el cual no se logra adherencia farmacológica. Durante el mes siguiente a su cirugía, logra desarrollar mejores rangos de movimiento, con $80^{\circ}$ de flexión, extensión completa, abducción a $35^{\circ}$, rotación externa a $30^{\circ}$ obteniendo un Score de Harris de 56,7. Se realiza un seguimiento en forma semestral, objetivando en controles posteriores rangos articulares limitados pero indoloros y radiología compatible con coxartrosis severa a derecha (-Fig. 2) por lo que en un futuro requerirá manejo con artroplastia.

\section{Discusión}

La $\mathrm{OH}$ es una condición que afecta a una minoría de los pacientes que requieren cuidados intensivos. Puede afectar a largo plazo la recuperación y su retorno funcional. ${ }^{4} \mathrm{Ha}$ sido descrita en pacientes con quemaduras severas, lesiones encefálicas y espinales, síndrome de distrés respiratorio agudo y en raros casos, pancreatitis. ${ }^{3}$ Debe tenerse en cuenta que cualquier paciente sometido a sedación prolongada es vulnerable. ${ }^{5}$ La prevalencia de $\mathrm{OH}$ se encuentra en un rango del $0,2 \%$ al $0,4 \%$ en pacientes quemados y puede elevarse hasta un $90 \%$ en casos seleccionados de artroplastia de cadera o fracturas acetabulares. Presenta preferencia por el sexo masculino, probablemente en relación a mayor masa muscular y vías hormonales diferentes involucradas en la 

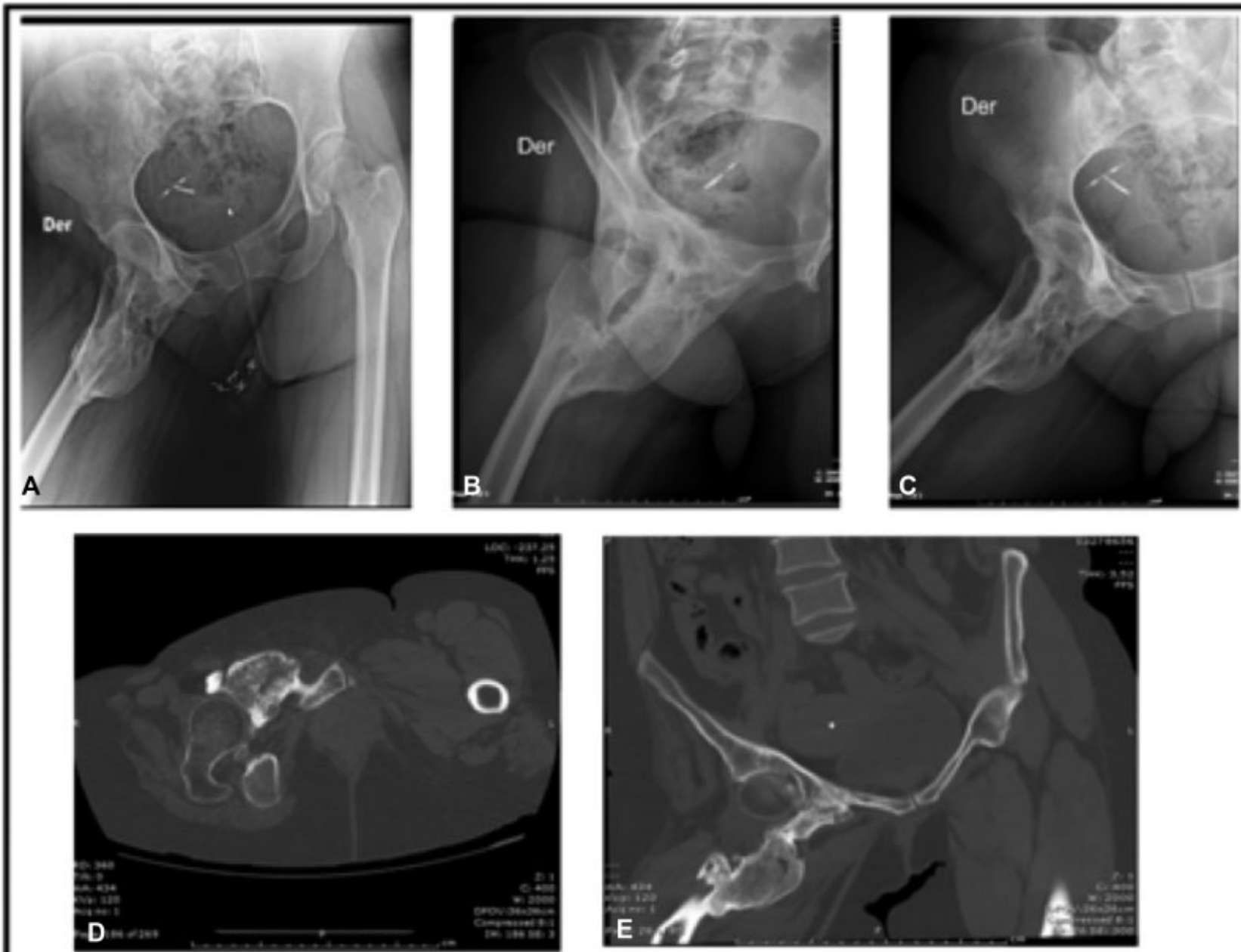

Fig. 1 Imágenes preoperatorias. (A) Proyección AP de pelvis año 2012, técnicamente limitada por rigidez, se aprecia en región coxofemoral anterior derecha una imagen amorfa, calcificada, bien definida, con un patrón trabecular establecido, sugerente de una osificación heterotópica madura. (B-C) Proyección lateral y cross-table de cadera derecha año 2016, técnicamente limitada por rigidez, se aprecia proceso sugerente de OH coxofemoral anterior derecha. (D-E) TAC de pelvis sin contraste año 2016, corte coronal y sagital donde se observa una lesión de gran tamaño, bien definida, uniendo en forma parcia al acetábulo, trocánter menor y rama del pubis, con corticales maduras y patrón de mineralización establecido.

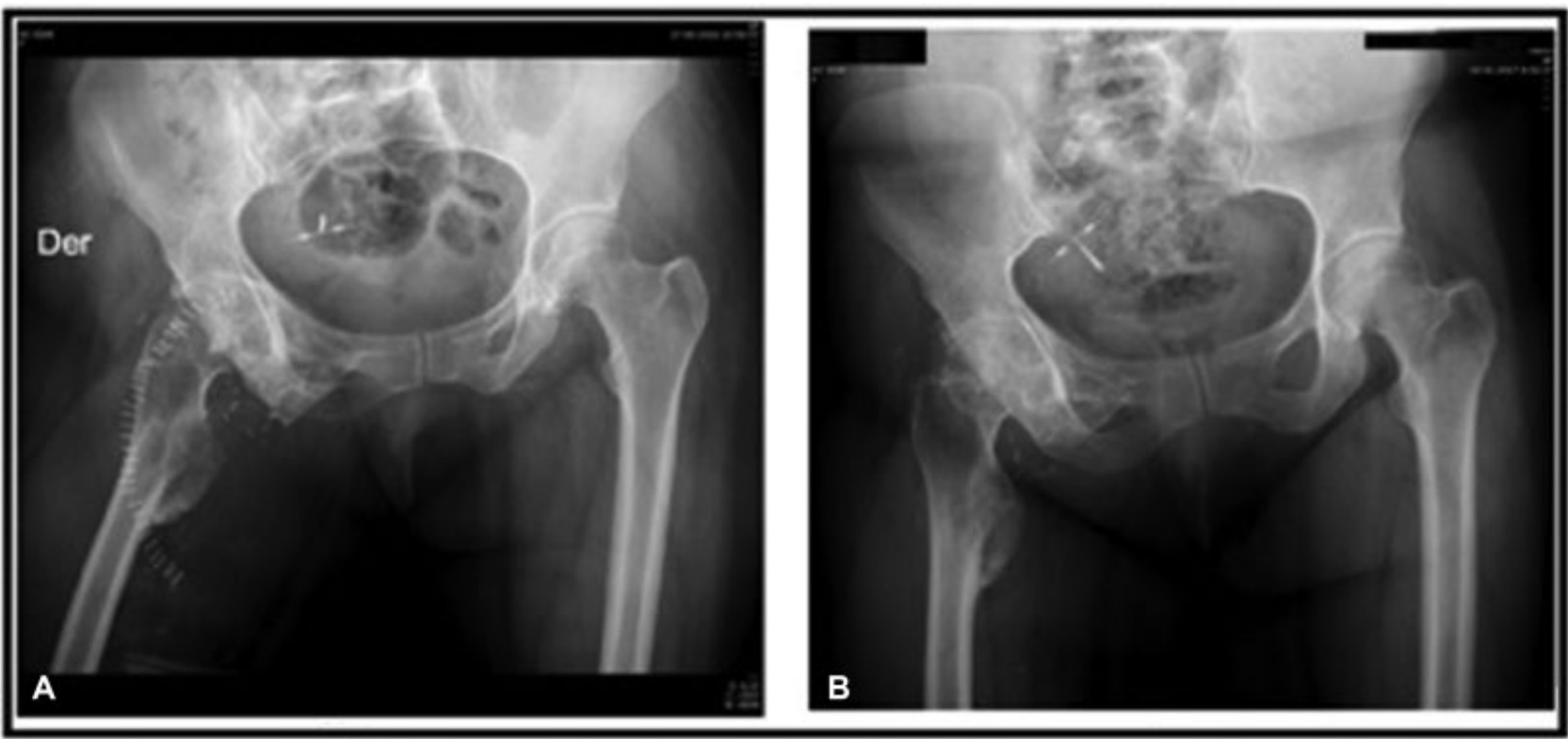

Fig. 2 Imágenes postoperatorias. (A) Proyección AP de pelvis 1ra semana post resección OH (2016) (B) Proyección AP de pelvis 6 meses post resección $\mathrm{OH}$ (2017). Se aprecian cambios degenerativos severos en la cadera derecha ya evidenciables en imágenes previas. 
osteogénesis. ${ }^{6}$ La presentación clínica de la $\mathrm{OH}$ es inespecífica e incluye dolor, inflamación, incluso fiebre. Se asocia habitualmente a la disminución de los rangos articulares normales, signos que muchas veces pueden pasar desapercibidos en pacientes que han presentado periodos prolongados de inmovilización y pueden ser enmascarados por la sedación y utilización de relajantes musculares. ${ }^{4}$

Su etiología exacta permanece aún sin ser totalmente comprendida, la mayor parte de su entendimiento proviene de la investigación en fibrodisplasia osificante progresiva, condición congénita que resulta en osificaciones heterotópicas en distintos segmentos corporales. La sobreactivación de la cascada de la proteína morfogénica ósea (BMP) produce la activación del receptor tipo 1 de activina (ACVR1), llevando finalmente a la osteogénesis anormal generada mediante osificación endocondral. ${ }^{7}$

El diagnóstico se basa en hallazgos clínicos y debe ser complementado con imagenología para definir su localización y extensión. Las radiografías tienen la ventaja de un costo reducido, sin embargo, no permiten visualizar la extensión de las lesiones en etapas precoces. La tomografía computada permite establecer la localización exacta de la $\mathrm{OH}$ en un plano tridimensional, permitiendo realizar una correcta planificación preoperatoria.

Nuevas técnicas de diagnóstico por imagen aún requieren de mayor evidencia para constituirse como indicaciones, tales como SPECT o ultrasonido. ${ }^{8}$ La profilaxis de la $\mathrm{OH}$ puede realizarse con antinflamatorios no esteroidales, sin embargo, sus riesgos deben tenerse en cuenta cuando ella se desarrolla en el contexto de una fractura, puesto que pueden producir retardos en la consolidación, como en el caso de la indometacina. ${ }^{9}$

Una Revisión Cochrane, que incluyó 16 ensayos de Nivel 1, demostró el beneficio del uso regular de indometacina durante la artroplastia total de cadera, la cual establece una reducción del $59 \%$ en la incidencia de la $\mathrm{OH}^{10-12} \mathrm{El}$ mecanismo de acción es a través de un efecto asociado de la inhibición de las células madre mesenquimales y la supresión de la inflamación por la inhibición de prostaglandinas. ${ }^{13}$ Sin embargo, se ha visto un porcentaje no menor de efectos secundarios gastrointestinales por lo que se prefiere el uso de los inhibidores de la COX-2.

La inhibición del crecimiento óseo por radiación, se estableció hace más de 50 años. ${ }^{14}$ Se ha demostrado que la exposición local preoperatoria o postoperatoria temprana de 7-8 Grays previene la formación de $\mathrm{OH} .{ }^{15} \mathrm{Al}$ tercer día del postoperatorio, las células madre mesenquimales ya se han diferenciado, y el tratamiento después de ese tiempo es poco efectivo. ${ }^{16}$

El uso de bifosfonatos se ha planteado en la profilaxis de la $\mathrm{OH}$, sin embargo, no existen estudios que validen su utilización rutinaria. Una revisión sistemática realizada en 2010 por Teasell y col., demuestra cierta utilidad en pacientes con trauma medular. ${ }^{17}$

Para su tratamiento se han planteado diversas modalidades, no invasivas o quirúrgicas.

Con respecto al uso de fisioterapia, no existe un consenso en su recomendación habitual. Parece ser útil en pacientes que experimentan empeoramiento en rango de movilidad producto de $\mathrm{OH}$, con limitación en sus actividades cotidianas. $^{18}$ No existe un tratamiento farmacológico establecido para la $\mathrm{OH}$, sin embargo, existen ensayos clínicos que demuestran la efectividad de agonistas del receptor de ácido retinoico en pacientes que padecen fibrodisplasia osificante progresiva. ${ }^{19}$

El tratamiento quirúrgico es efectivo en la $\mathrm{OH}$, considerándose como una opción en pacientes con déficit funcional. Dada la fragilidad en los tejidos blandos circundantes que habitualmente acompaña al desarrollo de la $\mathrm{OH}$, es importante informar a los pacientes sobre los riesgos de la cirugía, ellos incluyen el retardo de la cicatrización, lesión nerviosa y contracturas recurrentes. La etiología de la $\mathrm{OH}$ es importante al momento de considerar el tiempo en el que se realizará la cirugía, así como el grado de maduración ósea asociado. La $\mathrm{OH}$ de origen traumático puede ser resecada en un periodo de 6-9 meses, la $\mathrm{OH}$ asociada a trauma espinal en 12 meses, la $\mathrm{OH}$ producida por trauma encefálico, en tanto, debe ser resecada en un plazo de 18 meses. Todos esos tiempos son estimativos y se basan en el concepto de maduración ósea completa, que no está bien definido en la literatura., ${ }^{6}$.19 Finalmente, la recomendación es realizar la cirugía en caso de que exista un importante compromiso funcional del segmento alterado, en ausencia de respuesta al tratamiento conservador.

En el caso clínico presentado, existió demora en el diagnóstico inicial, determinada por la sobreposición de signología clínica mostrada por la paciente, con el déficit motor propio presentado por pacientes sometidos a largos periodos de inmovilización. A pesar de lo anterior, el retraso en el diagnóstico no influyó en su pronóstico final, como lo demuestra la revisión presentada.

\section{Conclusión}

La $\mathrm{OH}$ constituye una complicación poco frecuente en pacientes que han experimentado prolongados periodos de inmovilización, sin embargo, sus consecuencias pueden provocar considerables limitaciones funcionales. Un alto nivel de sospecha permite realizar un diagnóstico precoz en pacientes que no presentan alteraciones neurológicas y que no logran alcanzar rangos normales de movilidad luego de su egreso hospitalario e instauración de fisioterapia. Quedan aún muchos aspectos por investigar con respecto a la $\mathrm{OH}$ y deben realizarse mayores investigaciones clínicas con el fin de sustentar con evidencia intervenciones en esos pacientes.

\section{Centro de Referencia}

Hospital Traumatológico de Concepción, Universidad de Concepción, Concepción, Región del Bío - Bío, Chile.

\section{Fuente de financiamiento}

Sin financiamiento externo.

Conflictos de interés

Sin conflictos de interés. 


\section{Bibliografía}

1 Dejerne A, Ceillier A. Para osteo arthropathies des paraplegiques par lesión medullaire; etude clinique et radiographique. Ann Med 1918;(05):497

2 Mavrogenis AF, Soucacos PN, Papagelopoulos PJ. Heterotopic ossification revisited. Orthopedics 2011;34(03):177

3 Sugita A, Hashimoto J, Maeda A, et al. Heterotopic ossification in bilateral knee and hip joints after long-term sedation. J Bone Miner Metab 2005;23(04):329-332

4 Hudson SJ, Brett SJ. Heterotopic ossification-a long-term consequence of prolonged immobility. Crit Care 2006;10(06):174

5 Pape HC, Lehmann U, van Griensven M, Gänsslen A, von Glinski S, Krettek C. Heterotopic ossifications in patients after severe blunt trauma with and without head trauma: incidence and patterns of distribution. J Orthop Trauma 2001;15(04):229-237

6 Ranganathan K, Loder S, Agarwal S, et al. Heterotopic Ossification: Basic-Science Principles and Clinical Correlates. J Bone Joint Surg Am 2015;97(13):1101-1111

7 van Dinther M, Visser N, de Gorter DJ, et al. ALK2 R206H mutation linked to fibrodysplasia ossificans progressiva confers constitutive activity to the BMP type I receptor and sensitizes mesenchymal cells to BMP-induced osteoblast differentiation and bone formation. J Bone Miner Res 2010;25(06):1208-1215

8 PeroskyJE, Peterson JR, Eboda ON, et al. Early detection of heterotopic ossification using near-infrared optical imaging reveals dynamic turnover and progression of mineralization following Achilles tenotomy and burn injury. J Orthop Res 2014;32(11):1416-1423

9 Sagi HC, Jordan CJ, Barei DP, Serrano-Riera R, Steverson B. Indomethacin prophylaxis for heterotopic ossification after acetabular fracture surgery increases the risk for nonunion of the posterior wall. J Orthop Trauma 2014;28(07):377-383
10 Fransen M, Neal B. Non-steroidal anti-inflammatory drugs for preventing heterotopic bone formation after hip arthroplasty. Cochrane Database Syst Rev 2004 (3)

11 Matta JM, Siebenrock KA. Does indomethacin reduce heterotopic bone formation after operations for acetabular fractures? A prospective randomised study. J Bone Joint Surg Br 1997;79 (06):959-963

12 Haran M, Bhuta T, Lee B. Pharmacological interventions for treating acute heterotopic ossification. Cochrane Database Syst Rev 2004 (4)

13 Sell S, Willms R, Jany R, et al. The suppression of heterotopic ossifications: radiation versus NSAID therapy-a prospective study. J Arthroplasty 1998;13(08):854-859

14 Coventry MB, Scanlon PW. The use of radiation to discourage ectopic bone. A nine-year study in surgery about the hip. J Bone Joint Surg Am 1981;63(02):201-208

15 Lo TC, Healy WL, Covall DJ, et al. Heterotopic bone formation after hip surgery: prevention with single-dose postoperative hip irradiation. Radiology 1988;168(03):851-854

16 Teasell RW, Mehta S, Aubut JL, et al; SCIRE Research Team. A systematic review of the therapeutic interventions for heterotopic ossification after spinal cord injury. Spinal Cord 2010; 48(07):512-521

17 Sullivan MP, Torres SJ, Mehta S, Ahn J. Heterotopic ossification after central nervous system trauma: A current review. Bone Joint Res 2013;2(03):51-57

18 Shimono K, Tung WE, Macolino C, et al. Potent inhibition of heterotopic ossification by nuclear retinoic acid receptor- $\gamma$ agonists. Nat Med 2011;17(04):454-460

19 Garland DE. A clinical perspective on common forms of acquired heterotopic ossification. Clin Orthop Relat Res 1991;(263):13-29 